\title{
Three aspects of the Swiss term structure: an empirical survey
}

\author{
Petra Gerlach-Kristen
}

Published online: 1 March 2007

(C) Swiss Society for Financial Market Research 2007

\begin{abstract}
The term structure is an important transmitter of, and indicator for, monetary policy. This paper studies the Swiss term structure using monthly data from 1989 to 2005 . We study the impact of the new monetary policy strategy that the Swiss National Bank (SNB) adopted at the beginning of 2000 on three aspects of the term structure. First, we test the expectations hypothesis and find it confirmed at the short end of the yield curve. At the long end, time-varying term premia seem present. Second, we ask whether the yield curve contains information regarding future inflation and economic activity. We find that a steepening of the yield curve predicted an increase in economic activity in the short term before the change in policy strategy, but not thereafter. Third, we study the contemporaneous reaction of the term structure to macroeconomic conditions and conclude that the SNB's commitment to stabilizing inflation may have become more credible after the change in the monetary policy strategy.
\end{abstract}

Keywords Term structure $\cdot$ Switzerland

\section{JEL Classification E43}

\section{Introduction}

The term structure of interest rates plays an important role for monetary policy for at least three reasons. First, central banks typically conduct policy by setting or influencing a very short-term interest rate. While this is the operational target of policy, it does not directly influence inflation and economic activity, which are

P. Gerlach-Kristen $(\bowtie)$

Swiss National Bank and University of Basel. Börsenstrasse 15, 8022 Zürich, Switzerland e-mail: petra.gerlach@snb.ch. 
the ultimate objectives of policy. Instead, medium to longer-term rates matter more for economic conditions. If a long-term yield can be thought of as the expected yield on a position that rolls over short-term bills over the life time of a long-term bond, as implied by the expectations hypothesis, and if the market participants' expectations of these future rates are correct, the effect of a monetary policy change on the economy can be predicted fairly easily. The same is true if the long-term yield additionally contains a constant term premium which rewards investors for the default risk and for the uncertainty about market conditions at that point in the future when they sell the bond. If these term premia vary, however, judging the impact of a monetary policy change on the economy is difficult. Thus, determining whether time-varying term premia are present in the data is an important exercise. ${ }^{1}$

Second, the term structure can serve as an information variable for monetary policy. It has been demonstrated for a number of countries that the slope of the yield curve is a useful predictor for future inflation and the future state of economic activity. ${ }^{2}$ The Fisher equation, which states that the nominal interest rate over a given period is equal to the real interest rate plus expected inflation over that period, implies that the nominal yield curve can be thought of as the sum of the term structure of real yields and the term structure of expected inflation. Therefore, the yield curve may contain information on future inflation. However, if the central bank credibly commits to achieving a certain constant inflation rate several years ahead, the yield curve should contain no information regarding inflation at that horizon. Since market participants expect future short-term real rates to react to economic activity, the term structure also may contain information on future output. Obtaining good forecasts of future inflation and output is crucial for policymakers in setting interest rates. ${ }^{3}$ The information contained in the yield curve is particularly attractive because it is readily available and never revised. Moreover, it may be more reliable than survey data on the public's expectations since stakes are higher in that market participants actually may lose money if they make a mistake in forecasting. ${ }^{4}$

\footnotetext{
1 While from the perspective of economic research it is of interest to test whether the expectations hypothesis is rejected, from a monetary policy point of view the expectations hypothesis may be a useful framework for analysing the dynamics of the term structure even if it is rejected, provided that the rejections are not too "large".

2 Since monetary policy impacts on financial markets, Hildebrand (2006) emphasises that central banks have to compare the information contained in market prices with economic and monetary indicators in order to avoid the problem of "the dog chasing its tail".

3 Note that a response to activity is desirable even if policy squarely focuses on inflation, since activity forecasts future inflation (see e.g. Svensson 1997).

4 Woodford (1994) argues that inflation expectations may become self-fulfilling if the central bank mechanically responds to movements in the slope of the yield curve. Optimally, the central bank responds to the determinants of future inflation, not to expected inflation. Since the former influence the latter, this distinction is difficult in practice.
} 
Third, the response of the term structure to economic shocks depends on the market participants' expectations of the future course of monetary policy. If markets believe that policymakers ensure a fast return of inflation to equilibrium after a shock, only shorter-term rates should respond to movements in inflation. A strong reaction also of the long end indicates that market participants believe that the central bank's commitment to a stable rate of inflation is not fully credible.

This paper studies the term structure of interest rates in Switzerland using monthly data from January 1989 to November 2005. This is an interesting exercise since the Swiss National Bank (SNB) adopted a new monetary policy strategy in January 2000 that might have influenced the dynamics of the yield curve. We address three questions in detail. First, how are long and short-term rates linked? More specifically, is there evidence for time-varying term premia? Second, what information on future inflation and economic activity is contained in today's yield curve? Third, what can the term structure tell us about the market participants' expectations of future monetary policy and about the SNB's credibility?

The rest of the paper is structured as follows. Section 2 briefly reviews the international literature on the term structure and summarizes previous findings on Swiss data. Section 3 discusses the recent regime change in monetary policy. Section 4 presents the data and establishes a first set of characteristics of the Swiss yield curve for the whole sample and for the two subsamples before and after the adoption of the new monetary policy strategy in 2000. We find that the term structure has generally been upward sloping. Section 5 examines the expectations hypothesis. The data do not reject the hypothesis at the short end of the yield curve. At the long end, time-varying term premia seem present in the sample prior to the regime change in monetary policy. For data after January 2000, the expectations hypothesis is rejected neither at the long nor the short end, though this may be due to imprecise parameter estimates. Section 6 studies the information content of the term structure for future inflation and economic activity. An increase in the slope at the short end of the yield curve tended to forecast higher economic activity over the next six months before the change in monetary policy framework, but not thereafter. The term structure does not seem to reveal information on future inflation, which is compatible with the view that the SNB credibly promises to keep inflation low and stable. Section 7 investigates the reaction of the term structure to macroeconomic variables and finds that long-term yields respond less than short-term yields. Whereas before the introduction of the new policy framework all yields responded significantly to an increase in inflation, we find from 2000 onwards a reaction only for yields of up to four years. Changes in economic activity, by contrast, trigger a significant response of the entire term structure before and after the change in policy framework. We argue that these findings imply that the SNB's commitment to stabilizing inflation may have become more credible. Section 8 concludes. 


\section{Literature review}

The literature on the term structure of interest rates is enormous, with first studies dating back over a hundred years. ${ }^{5}$ This section therefore does not attempt to present a detailed survey. Instead, we focus on two central themes that have been addressed in the literature. The first is how yields of different maturity are related to one another. The workhorse in this extensive field is the expectations hypothesis (see Shiller 1990 for an overview of this literature and Cuthbertson 1996 for a textbook discussion). The expectations hypothesis implies that longterm yields are determined by the expected future path of short-term rates. Frequently, the linkages between yields of different maturities predicted by the expectations hypothesis are rejected by the data, suggesting the presence of time-varying term premia. ${ }^{6}$ One possible explanation is that the monetary policy and exchange rate regime matters for the dynamics of the term structure. In particular, Mankiw and Miron (1986) argue that the Fed's commitment to stabilizing interest rates caused the expectations hypothesis, which held before the Fed's founding in 1913, to fail thereafter. They also demonstrate that after the establishment of the Fed, it was more difficult to predict the future course of short-term rates. McCallum (1994) discusses that if monetary policy responds to the term spread, the expectations hypothesis in its original form ceases to hold, and Kugler (2002) provides empirical support for this theory using US data. ${ }^{7}$ Gerlach and Smets (1998) find that the expectations hypothesis fares better in countries where short-term rates are comparatively easy to forecast.

A second strand of literature focuses on the information content of the term structure for future inflation and economic activity. Fama (1990) and Mishkin (1990) provide evidence for a link between the slope of the term structure and future inflation in the US. Using monthly data from the early 1950s to the late 1980s, they find that a steepening in the yield curve tends to be associated with a future rise in inflation. This pattern can be explained by the fact that market participants demand higher nominal yields on bonds if they expect inflation to increase. Bernanke (1990), Estrella and Hardouvelis (1991) and Estrella and Mishkin (1998) find a link between the term spread and future US economic activity. Using data from roughly the end of the 1950s to the end of the 1980s, they document that an inverted yield curve generally predicts recessions. ${ }^{8}$ These results have been replicated for a number of other countries. Jorion and Mishkin (1991) confirm the finding that the slope of the yield curve forecasts future inflation in data for Germany, Switzerland (to be discussed in more detail below) and the UK for the period from 1973 to 1989. Estrella and Mishkin (1997) find that the term structure provides information

\footnotetext{
5 Shiller (1990) quotes an 1896 contribution by Fisher (1896).

6 The expectations hypothesis is generally more easily rejected at the long end of the yield curve. See Bisignano (1987); Hardouvelis (1994) offers several explanations for this finding.

7 See also Hsu and Kugler (1997).

8 The exact data samples are 1961 to 1989 in Bernanke (1990), 1955 to 1988 in Estrella and Hardouvelis (1991) and 1959 to 1995 in Estrella and Mishkin (1998).
} 
on future economic activity for France, Germany, Italy and the UK over the period from 1973 to 1995, and Bernard and Gerlach (1998) establish the same link for Belgium, Canada, France, Germany, Japan, the Netherlands and the UK for 1972 to 1993.

Despite Switzerland's important position in international financial markets, comparatively little work has been published on the Swiss term structure. In part, this may be due to the fact that the Swiss government bond market was illiquid up to the 1990s (see Jorion and Mishkin 1991) and that an analysis of the entire term structure therefore was not possible. As a way out, the available literature concentrates on the short end of the yield curve and examines the expectations hypothesis using euro Swiss franc rates with maturity of up to a year. Hsu and Kugler $(1996)$ and Kugler $(1988,1994)$ use euro rates starting in the late 1970s and ending in the late 1980s/early 1990s, respectively. They find that the spread between a medium and a short-term rate predicts future changes in the short-term rate. However, the impact of the spread is smaller than theory would suggest, and they therefore reject the expectations hypothesis. ${ }^{9}$ Gerlach and Smets (1997) study the term structure of euro rates for a number of countries, among them Switzerland. Using data from 1972 to 1993, they reject the expectations hypothesis at the short end of the Swiss term structure. Kugler (1988), finally, shows that the slope of the yield curve is a useful predictor for short-term rates in Germany and Switzerland for the period from 1974 to 1986, during which the Bundesbank and the SNB followed monetary targeting strategies, but no monetary target was in place in the US.

Mishkin (1991) and Jorion and Mishkin (1991) analyze whether the yield curve in Switzerland, among other countries, predicts future inflation. ${ }^{10}$ Mishkin uses euro rates with maturities of up to 12 months for the period from 1973 to 1986 and finds that, contrary to theory, an increase in the slope of the yield curve is associated with a fall in inflation. Jorion and Mishkin use euro Swiss franc rates with one to five years maturity for the period from 1973 to 1989 and find, as predicted by theory, that a steepening of the yield curve is associated with a rise in future inflation. The evidence on the information content of the term structure for future Swiss inflation is thus inconclusive. Unternährer (1997) shows that for data from 1974 to 1995, an increase of the slope of the Swiss term structure was associated with higher GDP growth two to six quarters ahead.

Since it has been argued that the dynamics of the term structure and, in particular, the validity of the expectations hypothesis depends on the monetary policy regime, we next briefly review Swiss monetary policy since the 1970s.

\footnotetext{
9 Kugler $(1996,1997)$ presents evidence that the Swiss term premium might be time-varying.

10 Büttler (2002) decomposes the yield curve into two separate term structures for expected inflation and the real interest rate, respectively. He finds that the inflation risk premium declined after the introduction of the new monetary policy regime at the beginning of 2000.
} 


\section{Swiss monetary policy regimes}

When the Bretton Woods system collapsed in 1973 and the Swiss franc was floated, the SNB adopted a monetary targeting regime. ${ }^{11}$ At first, annual growth targets for M1 were used, but these were abandoned in 1978 when demand for this monetary aggregate became unstable due to large exchange rate swings. The SNB then temporarily used an exchange rate objective, but returned to monetary targeting in 1980 by adopting an objective for the growth rate of M0. At the end of the 1980s, the introduction of an electronic interbank payment system led, among other factors, to instability in the demand of M0, so that, in 1991, the SNB switched to a multi-year growth target for a seasonally adjusted version of this monetary aggregate. From 1996 onwards, the M3 growth rate was used as an additional indicator for monetary policy.

In January 2000, the SNB introduced a new policy framework in which the prominence of monetary aggregates was reduced. ${ }^{12}$ The overriding goal of monetary policy-price stability - was quantified as inflation of below two percent, as measured by the annual change in the consumer price index. ${ }^{13}$ Changes in policy are based on the implications of a broadly-based inflation forecast, which makes use of real and monetary data. The forecast is published in the SNB's quarterly bulletin, has a horizon of three years and is made under the assumption of no future changes in the policy instrument. This instrument is the three-month LIBOR, and the SNB announces a target range of typically 100 basis points for this rate. While the choice of a threemonth rate rather than a shorter rate as policy instrument is unusual, this setup gives the SNB room to manoeuvre in case of sudden exchange rate movements. $^{14}$

It has been argued that the performance of the expectations hypothesis depends on the extent to which the central bank controls the short-term interest rate. We therefore study below the impact of the change from monetary targeting to a strategy that uses the 3-month rate as policy instrument on the dynamics of the term structure. We also assess whether the new policy strategy has affected the information content of the yield curve and the SNB's credibility. Before analyzing these issues, we discuss the data.

11 For a more detailed discussion of the history of monetary policy regimes in Switzerland, see Hildebrand (2004), Peytrignet (1999) and Rich (2003). On the role of money in the Swiss inflation process, see e.g. Assenmacher-Wesche and Gerlach (2005), Baltensperger et al. (2001), GerlachKristen (2006) and Jordan et al. (2001).

12 For a detailed discussion of the new policy framework, see SNB (1999).

13 While Mishkin (2002) classifies the SNB under the new regime as an inflation targeter, Baltensperger et al. (2003) and Olivei (2002) argue that the SNB has greater flexibility than a typical inflation targeter. For instance, the new strategy does not specify how fast inflation should return to a level consistent with price stability after a shock.

14 See also Jordan and Kugler (2003). 


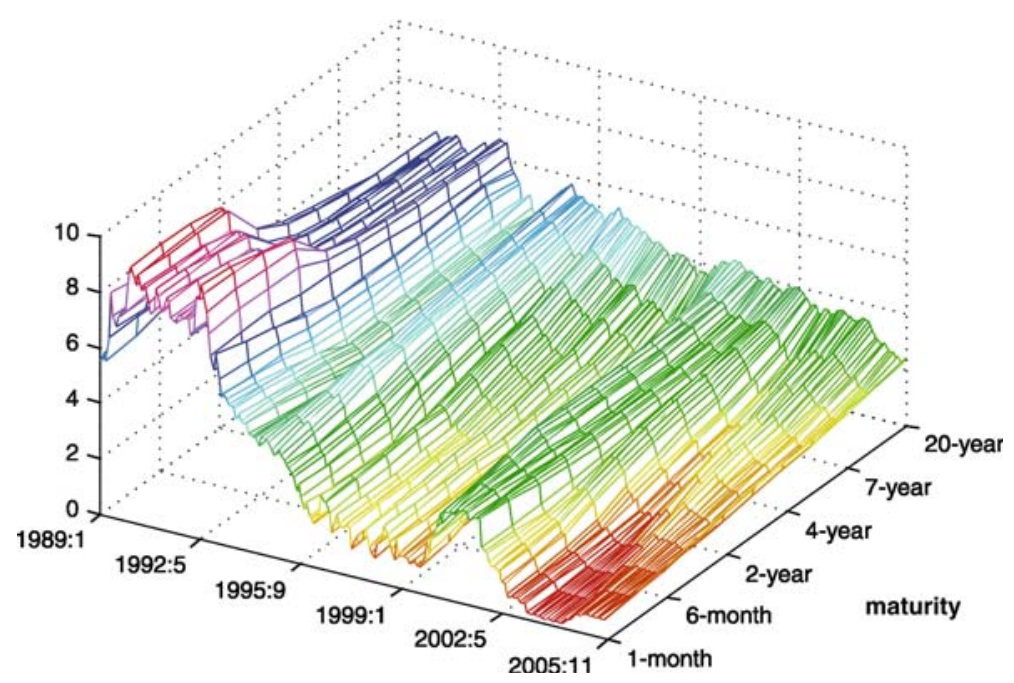

Fig. 1 Interest rate data. Continuously compounded interest rates, 1989:01 to 2005:11

\section{Data}

We use monthly interest rate data from January 1989 to November 2005, which are available from the SNB's website. To model the short end of the yield curve, we use 1-, 3-, 6- and 12-month money market rates. For the longer end, we use estimated zero-coupon yields with a maturity of 2, 3, 4, 5, 7, 10 and 20 years, which the SNB constructs from coupon bonds using the Nelson-Siegel method. ${ }^{15,16}$ All interest rate data are continuously compounded. It should be noted that the fact that we rely on two different data sources might account for certain differences we observe between long- and short-term rates. We return to this issue below.

Figure 1 plots the yield curve. We see that interest rates were comparatively high at the beginning of the sample, with short-term rates above 9 percent in early 1990 and in the spring of 1992. The level of the yield curve declined after 1992, but rose again with the tightening of monetary policy in the second half of 1999. Monetary loosening towards the end of 2001 led to a further decline in the level of the yield curve, while the renewed tightening of monetary conditions from the summer of 2004 onwards caused a slight increase.

\footnotetext{
15 The coupon bond yields are available on a daily basis for the entire sample period for all considered horizons. For details on the construction of the discount rates, see SNB (2002). On the estimation of zero-coupon yields for Switzerland, see also Bernanke (1990), Capitelli (1983), Deppner (1992), Heller (1997), Meier (1999) and Tobler (1999).

16 Since it is plausible that the results presented here are particular to the Nelson-Siegel data, we also performed the analysis using alternative SNB internal zero-coupon yields graciously provided by Hans-Jürg Büttler, which are available from 1998 onwards and which are based on the approach proposed by Cox et al. (1985) (see also Büttler 2002). The results are virtually identical.
} 
Table 1 Summary statistics for yield data

\begin{tabular}{llllllllllll}
\hline $\begin{array}{l}\text { Maturity } \\
\text { 1989:01 to 2005:11 }\end{array}$ & $1 \mathrm{~m}$ & $3 \mathrm{~m}$ & $6 \mathrm{~m}$ & $12 \mathrm{~m}$ & $2 \mathrm{y}$ & $3 \mathrm{y}$ & $4 \mathrm{y}$ & $5 \mathrm{y}$ & $7 \mathrm{y}$ & $10 \mathrm{y}$ & $20 \mathrm{y}$ \\
$\quad$ & & & & & & & & & & & \\
Mean & 3.38 & 3.43 & 3.46 & 3.52 & 3.37 & 3.43 & 3.54 & 3.65 & 3.85 & 4.08 & 4.50 \\
Median & 2.44 & 2.45 & 2.59 & 2.71 & 2.79 & 3.02 & 3.10 & 3.25 & 3.64 & 3.88 & 4.30 \\
Standard deviation & 2.77 & 2.74 & 2.68 & 2.57 & 2.07 & 1.83 & 1.68 & 1.58 & 1.44 & 1.29 & 1.03 \\
Skewness & 0.74 & 0.74 & 0.74 & 0.74 & 0.57 & 0.49 & 0.45 & 0.42 & 0.38 & 0.34 & 0.18 \\
Kurtosis & 2.17 & 2.19 & 2.20 & 2.22 & 2.03 & 1.98 & 1.96 & 1.96 & 1.97 & 2.03 & 2.42 \\
1989:1 to 1999:12 & & & & & & & & & & & \\
Mean & 4.45 & 4.49 & 4.50 & 4.51 & 4.18 & 4.17 & 4.23 & 4.32 & 4.48 & 4.68 & 5.02 \\
Median & 4.13 & 4.09 & 4.16 & 4.20 & 4.11 & 4.16 & 4.27 & 4.36 & 4.54 & 4.65 & 4.99 \\
Standard deviation & 2.79 & 2.75 & 2.69 & 2.57 & 2.02 & 1.77 & 1.61 & 1.50 & 1.34 & 1.16 & 0.83 \\
Skewness & 0.27 & 0.29 & 0.30 & 0.32 & 0.17 & 0.08 & 0.02 & -0.02 & -0.08 & -0.08 & 0.22 \\
Kurtosis & 1.54 & 1.54 & 1.54 & 1.56 & 1.54 & 1.59 & 1.65 & 1.73 & 1.85 & 1.97 & 2.04 \\
2000:01 2005:11 & & & & & & & & & & & \\
Mean & 1.39 & 1.45 & 1.52 & 1.68 & 1.86 & 2.07 & 2.25 & 2.40 & 2.67 & 2.97 & 3.53 \\
Median & 0.74 & 0.76 & 0.83 & 1.04 & 1.37 & 1.61 & 1.88 & 2.14 & 2.50 & 2.85 & 3.54 \\
Standard deviation & 1.17 & 1.18 & 1.18 & 1.16 & 1.06 & 0.94 & 0.85 & 0.77 & 0.68 & 0.60 & 0.56 \\
Skewness & 0.66 & 0.66 & 0.67 & 0.63 & 0.54 & 0.47 & 0.41 & 0.36 & 0.25 & 0.04 & -0.61 \\
Kurtosis & 1.81 & 1.80 & 1.84 & 1.86 & 1.76 & 1.71 & 1.69 & 1.70 & 1.78 & 2.00 & 2.76 \\
\hline
\end{tabular}

Continuously compounded interest rates, 1989:01 to 2005:11

$m$ months, $y$ years

The slope of the Swiss term structure has generally - with the exception of the period from 1989 to 1993 - been positive, which suggests the presence of term premia. This is also documented in Table 1 , which provides summary statistics for the different yields for the entire sample period and the subsamples before and after the change in monetary policy strategy. In all samples, both the mean and median tend to increase with maturity. It should, however, be noted that the mean of the 2-year rate lies below that of the 12-month rate, which might be due to the fact that the two series are drawn from different databases. The table also reports that the standard deviation of the yields is decreasing with maturity. This finding is compatible with the notion that news affect short-term yields more than long-term yields. The skewness, which captures any asymmetry of a distribution and which is larger than zero if yields above the mean are more frequent than yields below it, is positive for short maturities but declines for longer rates. For very long-term yields, the skewness turns negative in the two subsamples. Finally, there is no clear pattern over different time horizons for the kurtosis, which measures the presence of fat tails in a distribution. However, the kurtosis is smaller than three for all horizons, which means that the distribution is flatter than the normal. This finding seems to be due to the downward trend followed by interest rates over the sample: the fact that high (low) yields were observed mainly at the beginning (end) of the sample accounts for thin tails. Having reviewed the interest rate data, we now turn to testing the expectations hypothesis. 


\section{The expectations hypothesis}

\subsection{Theory}

The expectations hypothesis implies that an interest rate $i_{n, t}$ of maturity $n$ can be expressed as the average of the one-period interest rates $i_{1, t}$ between today and period $n-1$ plus, potentially, a term premium $\theta_{n, t}$. This premium reflects the fact that investors need to be compensated for any default risk and for the risk they face regarding the future price for which they can sell the bond. Formally, we have that

$$
i_{n, t}=\frac{1}{n} \sum_{j=0}^{n-1} E_{t} i_{1, t+j}+\frac{1}{n} \sum_{j=0}^{n-1} \theta_{n, t+j}
$$

Equation (1) implies that an upward-sloping term structure is compatible either with the expectation that short-term interest rates will rise or with positive term premia that increase with maturity. In the following, we denote $\sum_{j=0}^{n-1} \theta_{n, t+j}$ by $\Theta_{n, t}$.

The expectations hypothesis assumes that $\Theta_{n, t}=\Theta_{n}$ is constant. Following Cuthbertson (1996), it can then be shown that a more general version of Eq. (1) is given by

$$
i_{n, t}=\frac{1}{s} \sum_{j=0}^{s-1} E_{t} i_{m, t+j m}+\Theta_{n},
$$

where $s=n / m$ is an integer and $m<n$. Thus, above we considered $m=1$.

Equation (2) can be rearranged in two ways. The first of these says that the term spread should predict the future path of short-term rates:

$$
\sum_{j=1}^{s-1}(1-j / s) E_{t}\left(i_{m, t+j m}-i_{m, t+(j-1) m}\right)=i_{n, t}-i_{m, t}-\Theta_{n} .
$$

Hence, if the term structure is upward sloping, i.e. if $i_{n, t}>i_{m, t}$, and if this slope exceeds the term premium $\Theta_{n}$, the shorter-term rate is expected to rise. To avoid losing too many degrees of freedom by making forecasts several periods ahead, econometricians typically use Eq. (3) to test the expectations hypothesis at the short end of the yield curve, i.e. for small $m$ and $n .{ }^{17}$

The second version in which Eq. (2) can be rewritten is commonly used to test the expectations hypothesis at the long end of the term structure. Note that

17 If we estimated Eq. (3) for $n=10$ years ( $=120$ months) and $m=5$ years ( $=60$ months), the left-hand side variable would be $1 / 2\left(i_{60, t+60}-i_{60, t}\right)$. The fact that this spread is defined over 5 years and that our data sample spans just below 17 years implies that there would be only 3.4 independent observations. 
Eq. (2) can be re-formulated to yield

$$
E_{t} i_{n-m, t+m}-i_{n, t}=\frac{m}{n-m}\left(i_{n, t}-i_{m, t}-\Theta_{n}\right) .
$$

For $m=1$ and under the assumption that $i_{n-1, t+1} \approx i_{n, t+1}$, we obtain

$$
E_{t} i_{n, t+1}-i_{n, t}=\frac{1}{n-1}\left(i_{n, t}-i_{1, t}-\Theta_{n}\right)
$$

Supposing for simplicity that $\Theta_{n}=0$, a positive slope of the term structure thus would make us expect the long-term rate to increase between $t$ and $t+1$. Since this equation only involves a one-period forecast, it can be estimated in relatively short samples even if $n$ is large.

A rejection of the expectations hypothesis is in the literature commonly taken as sign of the presence of time-varying term premia. ${ }^{18}$ We next assess whether such premia are present in the Swiss yield curve by estimating Eq. (3) and (4).

\subsection{Empirical evidence}

In the estimation, we think of the short run as pertaining to maturities of at most one year. We test the expectations hypothesis at the short end of the yield curve by fitting

$$
\sum_{j=1}^{s-1}(1-j / s)\left(i_{m, t+j m}-i_{m, t+(j-1) m}\right)=\alpha+\beta\left(i_{n, t}-i_{m, t}\right)+e_{t},
$$

which has the same structure as Eq. (3), but where we now allow for a residual, $e_{t}$. Note that if the term premium on the $n$-period bond is positive and constant, we expect to find a negative $\alpha$. If the expectations hypothesis holds, we should not be able to reject that $\beta$ equals unity.

We estimate Eq. (5) with OLS and report Newey-West standard errors to account for overlapping observations. As maturities we consider $m=1,3,6$ and 12 months and $n=3,6$ and 12 months. We use data from December 2004 as last observation, which ensures that the same sample period is considered for all combinations of $m$ and $n$. The estimation output for the full sample and the two subsamples is documented in Table 2.

We find that the constant $\alpha$ is significantly different from zero and decreases further as we raise $n$ relative to $m$. This indicates that the term premia are increasing in maturity. While we find that all point estimates of $\beta$ lie below

18 An alternative explanation would be that economic agents make errors in the formation of expectations. Boudoukh et al. (2005) suggest peso problems and the violation of rational expectations as examples. 
Table 2 Estimation output for the short end of the yield curve $\sum_{j=1}^{s-1}(1-j / s)\left(i_{m, t+j m}-i_{m, t+(j-1) m}\right)=\alpha+\beta\left(i_{n, t}-i_{m, t}\right)+e_{t}$

\begin{tabular}{|c|c|c|c|c|c|c|}
\hline \multicolumn{6}{|l|}{$1989: 01$ to $2004: 12$} & 6 month \\
\hline$n$ & $3 \mathrm{~m}$ & $6 \mathrm{~m}$ & $12 \mathrm{~m}$ & $6 \mathrm{~m}$ & $12 \mathrm{~m}$ & $12 \mathrm{~m}$ \\
\hline$\alpha$ & $-0.061 * *$ & $-0.129 * *$ & $-0.260 * * *$ & -0.061 & $-0.185^{* *}$ & $-0.114^{*}$ \\
\hline$\beta$ & $0.740 * * *$ & $0.809 * * *$ & $0.713 * * *$ & $0.765^{* * *}$ & $0.594 * *$ & 0.442 \\
\hline$R^{2}$ & 0.137 & 0.190 & 0.175 & 0.107 & 0.094 & 0.039 \\
\hline$p$-value for $\alpha=0$ & 0.011 & 0.013 & 0.006 & 0.069 & 0.028 & 0.079 \\
\hline$p$-value for $\beta=1$ & 0.058 & 0.204 & 0.186 & 0.226 & 0.128 & 0.104 \\
\hline \multicolumn{7}{|l|}{$1989: 01$ to $1999: 12$} \\
\hline$n$ & $3 \mathrm{~m}$ & $6 \mathrm{~m}$ & $12 \mathrm{~m}$ & $6 \mathrm{~m}$ & $12 \mathrm{~m}$ & $12 \mathrm{~m}$ \\
\hline$\alpha$ & $-0.055^{*}$ & -0.106 & $-0.198 *$ & -0.045 & -0.133 & -0.082 \\
\hline$\beta$ & $0.689 * * *$ & $0.780 * * *$ & $0.697 * *$ & $0.757 * * *$ & $0.600^{*}$ & 0.493 \\
\hline$R^{2}$ & 0.111 & 0.158 & 0.146 & 0.088 & 0.078 & 0.037 \\
\hline$p$-value for $\alpha=0$ & 0.082 & 0.118 & 0.096 & 0.316 & 0.206 & 0.296 \\
\hline$p$-value for $\beta=1$ & 0.034 & 0.218 & 0.274 & 0.311 & 0.258 & 0.244 \\
\hline \multicolumn{7}{|l|}{$2000: 01$ to $2004: 12$} \\
\hline$n$ & $3 \mathrm{~m}$ & $6 \mathrm{~m}$ & $12 \mathrm{~m}$ & $6 \mathrm{~m}$ & $12 \mathrm{~m}$ & $12 \mathrm{~m}$ \\
\hline$\alpha$ & $-0.088 * * *$ & $-0.208 * * *$ & $-0.519 * * *$ & $-0.116 * * *$ & $-0.408 * * *$ & $-0.248^{* * *}$ \\
\hline$\beta$ & $1.039 * * *$ & $1.044 * * *$ & $1.134 * * *$ & $1.024 * * *$ & $1.055 * * *$ & $0.824 *$ \\
\hline$R^{2}$ & 0.427 & 0.473 & 0.508 & 0.326 & 0.391 & 0.187 \\
\hline$p$-value for $\alpha=0$ & 0.003 & 0.001 & 0.000 & 0.002 & 0.000 & 0.001 \\
\hline$p$-value for $\beta=1$ & 0.894 & 0.868 & 0.589 & 0.938 & 0.867 & 0.730 \\
\hline
\end{tabular}

OLS estimates for Eq. (5), Newey-West standard errors

$* / * * / * * *$ denotes significance at the ten/five/one percent level. $p$-values are for Wald coefficient tests

unity, we reject the hypothesis that $\beta$ equals unity only for the spread between the 1- and 3-month rates, and only if we include data before the regime change in monetary policy. Overall, this suggests that the expectations hypothesis is reflected by the short end of the Swiss yield curve, i.e. that there is no evidence in support of time-varying term premia.

It is interesting to note that Hsu and Kugler (1996), Kugler $(1988,1994)$ and Gerlach and Smets (1997), who use data ending in the late 1980s and early 1990s, respectively, reject the expectations hypothesis at the short end of the Swiss yield curve. Thus, it seems that the dynamics of the term structure have changed. In particular, the term premia do not appear to vary with time anymore. We leave the question what might have caused this change for future research.

We next focus on the long end of the term structure and fit the empirical version of Eq. (4), i.e.

$$
i_{n, t+1}-i_{n, t}=\alpha+\beta \frac{1}{n-1}\left(i_{n, t}-i_{1, t}\right)+e_{t},
$$

where $i_{1, t}$ is the one-month rate. As maturity $n$ we use 2, 3, 4, 5, 7, 10 and 20 years. Table 3 reports the parameter estimates and White standard errors for the period from January 1989 to October 2005 and for the two subsamples. 
Table 3 Estimation output for the long end of the yield curve $i_{n, t+1}-i_{n, t}=\alpha+\beta \frac{1}{n-1}\left(i_{n, t}-i_{1, t}\right)+e_{t}$

\begin{tabular}{lrrrrrrr}
\hline $1989: 01$ to $2005: 12$ & & & & & \\
$n$ & 2year & 3year & 4year & 5year & 7year & 10year & 20 year \\
$\alpha$ & -0.017 & -0.014 & -0.011 & -0.009 & -0.005 & -0.002 & 0.002 \\
$\beta$ & -0.468 & -0.643 & -0.796 & -0.943 & -1.230 & $-1.619^{*}$ & -2.549 \\
$R^{2}$ & 0.004 & 0.008 & 0.010 & 0.012 & 0.015 & 0.017 & 0.014 \\
p-value for $\alpha=0$ & 0.334 & 0.396 & 0.470 & 0.550 & 0.712 & 0.908 & 0.875 \\
p-value for $\beta=1$ & 0.016 & 0.010 & 0.008 & 0.006 & 0.005 & 0.006 & 0.030 \\
1989:01 to 1999:12 & & & & & & & \\
$\alpha$ & -0.025 & -0.020 & -0.016 & -0.012 & -0.007 & -0.002 & 0.005 \\
$\beta$ & -0.693 & -0.825 & -0.954 & -1.088 & -1.362 & -1.723 & -2.418 \\
$R^{2}$ & 0.009 & 0.012 & 0.014 & 0.016 & 0.019 & 0.019 & 0.012 \\
p-value for $\alpha=0$ & 0.293 & 0.347 & 0.417 & 0.498 & 0.676 & 0.908 & 0.783 \\
p-value for $\beta=1$ & 0.018 & 0.014 & 0.012 & 0.011 & 0.009 & 0.012 & 0.074 \\
$2000: 01$ to $2005: 12$ & & & & & & & -0.012 \\
$\alpha$ & -0.030 & -0.019 & -0.013 & -0.011 & -0.010 & -0.011 & -0.013 \\
$\beta$ & 0.688 & 0.111 & -0.268 & -0.483 & -0.682 & -0.839 & -1.405 \\
$R^{2}$ & 0.004 & 0.000 & 0.000 & 0.001 & 0.001 & 0.001 & 0.002 \\
p-value for $\alpha=0$ & 0.402 & 0.578 & 0.689 & 0.741 & 0.761 & 0.747 & 0.710 \\
p-value for $\beta=1$ & 0.863 & 0.582 & 0.452 & 0.404 & 0.407 & 0.454 & 0.494 \\
\hline
\end{tabular}

OLS estimates for Eq. (6), White standard errors

$* / * * / * * *$ denotes significance at the ten/five/one percent level. $p$-values are for Wald coefficient tests

In contrast to the analysis for the short end of the yield curve, we do not reject the hypothesis that $\alpha$ equals zero. We moreover find that $\beta$ is negative and that the larger $n$ is, the larger $\beta$ is in absolute value. The estimates of $\beta$ differ significantly from unity for all maturities if we include data prior to 2000 . Thus, the expectations hypothesis is rejected at the long end of the yield curve, indicating the presence of time-varying term premia. In the second subsample, by contrast, the hypothesis that $\beta=1$ is not rejected. Indeed, the estimates for $\beta$ are positive for maturities of two and three years, and for longer maturities, they are also closer to unity than in the first subsample. The fact that we do not reject the hypothesis that $\beta=1$ is, however, at least in part due to large estimated standard errors, which in turn might be related to the short sample size. The $R^{2}$ of the regressions in Table 3 are close to zero, suggesting that the term spread is a poor predictor of movements at the long end of the yield curve.

The finding of a negative $\beta$ is common in the literature (see e.g. Bisignano 1987). ${ }^{19}$ Mankiw and Miron (1986) show that a negative $\beta$ may arise if the term premium is not constant. Depending on the variability of $\Theta_{n, t}, i_{n, t+1}-i_{n, t}$ and their covariance, Hardouvelis (1994) demonstrates that the estimated value for $\beta$ obtained from Eq. (6) can be positive or negative and smaller or larger than unity.

It should also be noted that the better performance of the expectations hypothesis at the short end of the term structure might in principle be due to

19 Boudoukh et al. (2005) present evidence suggesting that an anomaly in the behavior of short-term interest rates is responsible for the rejection of the expectations hypothesis. 
the fact that the yields with maturities of up to one year are money market rates, whereas the longer yields are constructed from coupon yields. However, if we fit Eq. (6) with $n=12$ months, we obtain an estimate of $\hat{\beta}=0.51$, which does not differ significantly from zero. Interestingly, this $\hat{\beta}$ is smaller than the estimate reported for the 1- and the 12-month spread in Table 2, which was equal to 0.71 , indicating that the approximation $i_{n-1, t+1} \approx i_{n, t+1}$ is poor for small $n$. This suggests that the two different data sources are not responsible for the acceptance of the expectations hypothesis at the short end of the yield curve and its rejection at the long end.

Overall, this section demonstrates that the expectations hypothesis holds at the short end of the Swiss yield curve. At the long end, the hypothesis is rejected in samples starting prior to 2000 , whereas there is some evidence that it might hold under the new policy regime. It nevertheless seems that time-varying term premia account for a considerable fraction of the movements at the long end of the Swiss term structure, and it would be desirable to model these premia explicitly. However, this is beyond the scope of this paper. Instead, we next examine what information the term structure contains on future inflation and economic activity (Sect. 6) and on the credibility of monetary policy (Sect. 7).

\section{Information content of the yield curve}

In this section, we examine whether the Swiss yield curve contains information about future inflation and economic activity over the period from 1989 to 2005. Figure 2 shows the annual rate of inflation and the unemployment rate. We use the unemployment rate rather than industrial production or output gap data since they are available on a monthly basis. ${ }^{20}$

We see that inflation almost tripled between 1989 and mid-1991, but declined from the second half of 1991 onwards. Inflation jumped up at the beginning of 1995, when a value-added tax was introduced (see Rich 2003, and again in 1999, when oil prices rose sharply. Unemployment increased as inflation began to fall in 1991 and stayed comparatively high until the mid-1990s. After a peak of 5.7 percent in 1997, the unemployment rate declined to below two percent in 2000 , but then increased once more. At the end of the sample, inflation stands at 0.9 percent and unemployment at 3.7 percent.

To assess if the term structure contains information regarding future changes in inflation and unemployment, we test whether the slope of the yield curve, $i_{n, t}-i_{m, t}$, forecasts the change in annual inflation over the horizon $n-m .^{21}$ To check for the possibility that the term spread does not contain any information beyond that already embedded in the current inflation rate, we also include the

20 Over our sample period, the correlation between quarterly unemployment and an HP-filtered output gap is -0.847 . It thus seems to be a good proxy for economic activity.

21 It should be noted that Jorion and Mishkin (1991) and Mishkin (1991) consider the difference between the forward inflation rates (i.e. the inflation rate between $t+m$ and $t+n$, which for $m=1$ month and $n=3$ months is a 2-month rate) as left-hand side variable, instead of $\pi_{t+n}-\pi_{t+m}$. We do not follow this course since short-term inflation rates in Switzerland are highly volatile. 
Fig. 2 Inflation and unemployment. Annual inflation rate and unemployment rate, 1989:01 to $2005: 11$

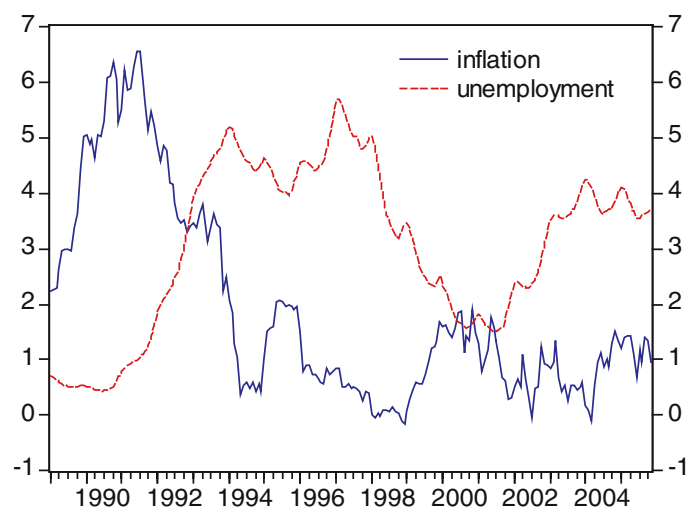

current $\pi_{t}{ }^{22}$ We thus fit

$$
\pi_{t+n}-\pi_{t+m}=A+B\left(i_{n, t}-i_{m, t}\right)+C \pi_{t}+v_{t} .
$$

It should be noted that the problem of overlapping observations is again present in Eq. (7) so that the estimates of $A$ to $C$ may be subject to a small sample bias. It is therefore desirable to compute empirical p-values. In Table 4 we present the estimate of $B$ for $m=1,3$ and 6 months and $n=3,6$ and 12 months for the period from January 1990 to November 2004 and for the two subsamples that result from splitting the data in January 2000, and we report both asymptotic and empirical significance levels, the latter being obtained using bootstrapping, in the left panel of Table $4 .^{23,24}$ The estimations suggest that the slope of the yield curve does not predict Swiss inflation, which contrasts the findings of Mishkin (1991) and Jorion and Mishkin (1991) for the 1970s and 80s, but which is compatible with the notion that the SNB credibly promises to keep inflation stable.

Next, we consider whether the yield curve predicts changes in unemployment. The right panel of Table 4 shows the estimates of $B$ in

$$
u_{t+n}-u_{t+m}=A+B\left(i_{n, t}-i_{m, t}\right)+C u_{t}+v_{t}
$$

There is some evidence of a small sample bias. Whereas the estimate of the slope coefficient is significant in 16 cases according to the asymptotic $p$-values, it is significant in only six cases if we consider the empirical $p$-values. In particular, a

\footnotetext{
22 Adding lagged inflation tends not to improve the fit of Eq. (7).

23 We do not consider forecasting horizons longer than 12 months since preliminary regressions suggested no predictive power of the term spread over longer horizons.

24 To obtain these, we model inflation (and, for the right panel of Table 4, unemployment) and the interest rate spreads as $\mathrm{AR}(12)$ processes. Using those parameter estimates and permutating the residuals, we construct 1,000 new series for each variable, compute the inflation (unemployment) rate and fit Eq. (7) (Eq. (8)). We calculate the $p$-value as the share of estimates of $B$ exceeding in absolute value the one obtained with the original data.
} 
Table 4 Information content for inflation and unemployment

$\pi_{t+n}-\pi_{t+m}=A+B\left(i_{n, t}-i_{m, t}\right)+C \pi_{t}+v_{t}$ and $u_{t+n}-u_{t+m}=A+B\left(i_{n, t}-i_{m, t}\right)+C u_{t}+v_{t}$

\begin{tabular}{|c|c|c|c|c|c|c|}
\hline \multirow{3}{*}{$\begin{array}{l}\text { 1990:01 to } 2004: 11 \\
\quad \begin{array}{l}m \\
n\end{array}\end{array}$} & \multicolumn{6}{|c|}{ Information content for } \\
\hline & \multicolumn{3}{|c|}{ inflation } & \multicolumn{2}{|l|}{ unemployment } & \multirow{3}{*}{$6 \mathrm{~m}$} \\
\hline & $1 \mathrm{~m}$ & $3 \mathrm{~m}$ & $6 \mathrm{~m}$ & $1 \mathrm{~m}$ & $3 \mathrm{~m}$ & \\
\hline $\begin{array}{l}n \\
3 \mathrm{~m}\end{array}$ & -0.819 & & & $-0.525 * * *++$ & & \\
\hline $6 \mathrm{~m}$ & -0.348 & 1.492 & & $-0.882 * * *++$ & $-0.884 * * *+$ & \\
\hline $12 \mathrm{~m}$ & -0.474 & 1.049 & -0.595 & $-0.841 * * *$ & $-1.104 * *$ & $-0.566^{*}$ \\
\hline \multicolumn{7}{|l|}{$\begin{array}{l}1990: 01 \text { to } 1999: 12 \\
\quad n\end{array}$} \\
\hline $3 \mathrm{~m}$ & -0.815 & & & $-0.517 * * *++$ & & \\
\hline $6 \mathrm{~m}$ & -0.615 & 0.979 & & $-0.966^{* * *++}+$ & $-1.047^{* * *+}+$ & \\
\hline $12 \mathrm{~m}$ & -0.963 & -0.204 & -1.242 & $-1.013 * * *$ & $-1.700 * * *$ & $-0.862 * *$ \\
\hline \multicolumn{7}{|l|}{$\begin{array}{l}2000: 01 \text { to } 2004: 11 \\
\quad n\end{array}$} \\
\hline $3 \mathrm{~m}$ & -0.500 & & & $-0.579 * * *$ & & \\
\hline $6 \mathrm{~m}$ & -0.601 & 0.683 & & $-0.721 * * *$ & $-0.661 * * *$ & \\
\hline $12 \mathrm{~m}$ & 0.150 & 2.613 & 0.393 & $-0.634^{*}$ & -0.322 & -0.157 \\
\hline
\end{tabular}

OLS estimates of B in Eqs. (7) and (8), Newey-West standard errors

$* / * * / * * *$ denotes asymptotic significance at the ten/five/one percent level, +/++/+++ empirical significance (obtained using bootstrapping, 1,000 draws) at the same levels

widening of the spreads between the 1-, the 3- and the 6-month yields predicts a fall in unemployment and hence a pickup in economic activity for the full sample and the first subsample. This evidence is compatible with Unternährer (1997), who, using quarterly GDP growth data, reports that an increase of the average long-term yield relative to the 3-month rate is associated with higher growth two to six quarters ahead. ${ }^{25}$ Interestingly, the predictive power of the term structure for future economic activity seems to have disappeared in the sample starting in 2000.

Overall, this section suggests that the yield curve helped predict economic activity, but not inflation, over the next 6 months before the change in monetary policy. Since 2000, the term structure seems to have contained information on neither of these two variables. Having studied the information regarding future economic activity and inflation embedded in the yield curve, we next turn to the question what the term structure reveals about the credibility of monetary policy.

\section{Macroeconomic determinants of the yield curve}

This section studies how the Swiss yield curve responds to changes in inflation and unemployment, which allows us to assess the credibility of monetary policy.

\footnotetext{
25 The SNB used to publish this average yield for government bonds of different maturity. See also SNB (1983).
} 
If market participants think that the central bank is committed to achieving a certain inflation rate, they expect monetary policy to react to movements in inflation and output to bring about a fast return to equilibrium. Consequently, shocks should affect interest rates at the short but not at the long end of the yield curve.

To study how the term structure as a whole depends on inflation and unemployment, we estimate regressions that take a form similar to empirical reaction functions (see Taylor 1993), so that

$$
i_{n, t}=\mu_{n}+a_{n} \pi_{t}+b_{n} u_{t}+c_{n} i_{n, t-1}+w_{n, t} .
$$

As is common in the literature on monetary policy reaction functions, we include a lagged interest rate to capture any remaining dynamics in the yields that are not explained by inflation or economic activity (see e.g. Clarida et al 1998). It should be noted that we assume that inflation and unemployment do not react contemporaneously to interest rates, which, given that we use monthly data, seems plausible. We fit Eq. (9) for all 11 maturities (i.e. for $n=1$ month to $n=20$ years) as a system allowing for the innovations $w_{n, t}$ to be correlated across equations. ${ }^{26}$

Figure 3 plots the long-run reaction of yields to inflation and unemployment, i.e. the estimates of $a_{n} /\left(1-c_{n}\right)$ and $b_{n} /\left(1-c_{n}\right)$, for the full sample and the two subsamples. ${ }^{27}$ We see that short-term rates react more to inflation and unemployment than long-term rates. The smaller response at the long end of the yield curve is compatible with the notion that the central bank attempts to return the economy fast to equilibrium after a shock. Interestingly, there is a jump in the reaction coefficients from $n=12$ months to $n=2$ years, which again might be due to the different origin of the short and long-term yield data.

Turning to the significance of the parameter estimates, we find that the response to unemployment is significant for all maturities and samples. ${ }^{28}$ The response to inflation is significant for all maturities in the whole sample. If only data before 2000 are used, the response of the 20 -year yield is insignificant, suggesting that an inflation shock had a long but not permanent impact. If we consider data generated under the new policy regime, the impact is significant only up to four years. This could be interpreted to suggest that market participants think that inflation is stabilized faster today than it used to be. However, the absence of major inflationary shocks since the adoption of the new monetary policy strategy might be responsible for this finding.

These results indicate that the new policy framework may have improved the credibility of the SNB's commitment to low and stable inflation. This conclusion is not specific to the present study; Büttler (2002) and Gerlach-Kristen (2005)

\footnotetext{
26 Simple OLS estimates allow the same conclusions as the SUR estimates presented here.

27 The conclusions are virtually identical if one considers the short-term reaction coefficients a and $\mathrm{b}$. In particular, long rates do not appear to react to inflation anymore after the change in the monetary policy framework.

28 We obtained the standard errors using the delta method (see e.g. Greene 1997).
} 

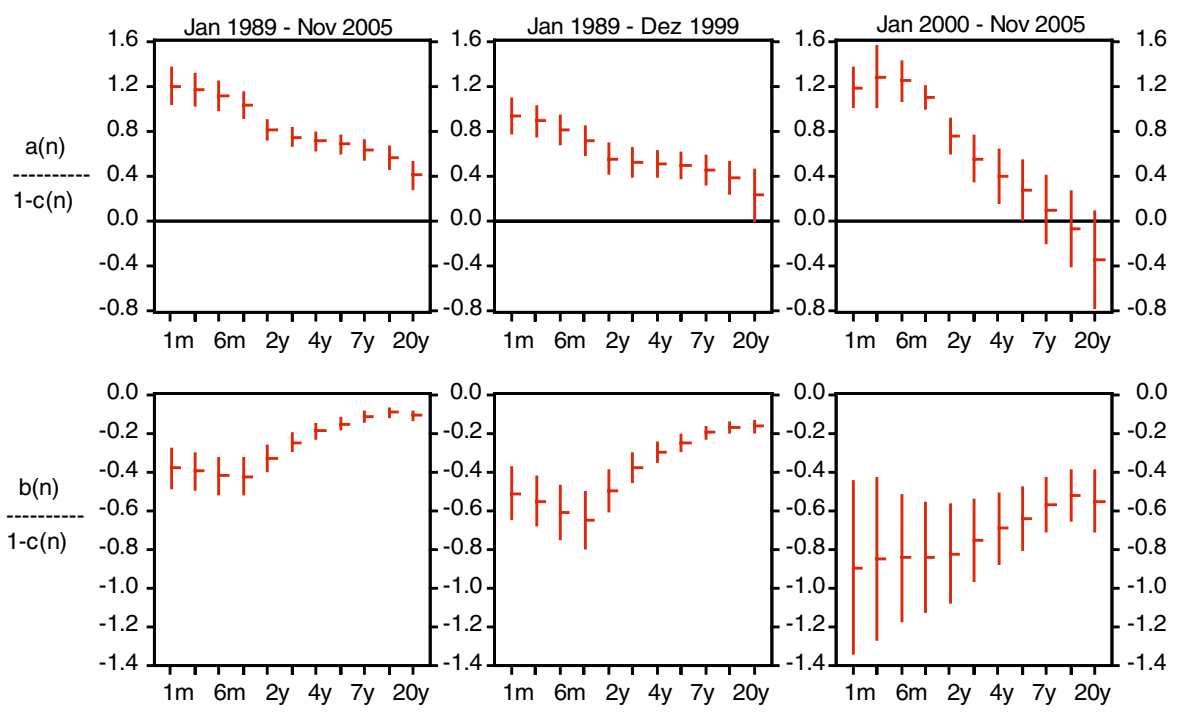

Fig. 3 Long-run reaction coefficients of the term structure $i_{n, t}=\mu_{n}+a_{n} \pi_{t}+b_{n} u_{t}+c_{n} i_{n, t-1}+w_{n, t}$. Estimates of coefficients $a_{n} /\left(1-c_{n}\right)$ and $b_{n} /\left(1-c_{n}\right)$ in Eq. (9) with $95 \%$ confidence band, estimation periods 1989:01 to 2005:11, 1989:01 to 1999:12 and 2000:01 to 2005:11

also find evidence of an impact of the new regime on market participants' inflation expectations. However, it has to be pointed out that here, we assume that the change in pattern occurred when the new policy strategy was adopted. An alternative and more elegant approach, which, however, is beyond the scope of this survey, would be to let the data speak as to if and when the reaction of the term structure to inflation and unemployment changed. The data might for instance identify a "disinflation" and a "stable inflation" regime, under which the responses of the term structure to economic shocks differ ${ }^{29}$ We leave the exploration of this hypothesis for future research.

\section{Conclusions}

This paper presents a systematic study of the Swiss term structure of interest rates. This exercise is interesting because the new monetary policy strategy, which the SNB adopted in 2000, may have affected the dynamics and the information content of the term structure.

We use monthly interest rates from 1989 to 2005 to test the expectations hypothesis for the whole sample and the period before and after the change in policy strategy, to assess the information content of the yield curve for future inflation and economic activity and to study the SNB's credibility. We find that the expectations hypothesis is not rejected at the short end of the term structure, but that at the long end time-varying term premia appear to matter. However,

29 I thank Marcel Savioz for making this point. 
their importance seems to have declined since the change to the new policy framework. A steepening at the short end of the yield curve appears to have forecast a rise in economic activity, but not inflation, within the next half year before the change in policy strategy. Since 2000, the slope of the yield curve does not appear to predict changes in either variable. Finally, after 1999, inflationary shocks have had a smaller impact on long-term rates, which might indicate that the SNB's commitment to low and stable inflation has been viewed as more credible under the new policy regime.

One important caveat is the question whether the change in the response of the yield curve to economic shocks is due to the new monetary policy framework or caused by other factors (and happened at a date other than the beginning of 2000), such as the switch from an environment of disinflation to one of low and stable inflation. A second caveat is that some of the results suggesting a different behavior at the long and the short end of the yield curve may in part be due to the fact that the data originate from two data sources. We leave the exploration of these issues for future research.

Acknowledgments The views expressed in this paper are the author's and do not necessarily reflect those of the Swiss National Bank. I thank Katrin Assenmacher-Wesche, Hans-Jürg Büttler, Stefan Gerlach, Thomas Jordan, Gero Jung, Peter Kugler, Angelo Ranaldo, Marcel Savioz, the members of the Ausschuss für Geldtheorie und Geldpolitik des Vereins für Socialpolitik and two anonymous referees for helpful comments.

\section{References}

Assenmacher-Wesche, K., Gerlach, S.: Money growth, output gaps and inflation at low and high frequency: Spectral estimates for Switzerland. mimeo, BIS and SNB (2005)

Baltensperger, E., Fischer, A.M., Jordan, T.J.: Abstaining from inflation targets: Understanding the importance of strong goal independence, mimeo, SNB and University of Bern (2003)

Baltensperger, E., Jordan, T.J., Savioz, M.: The demand for M3 and inflation forecasts: an empirical analysis for Switzerland. Weltwirtschaftliches Archiv 137(2), 244-272 (2001)

Beer, U.: Eine Methode zur Schätzung der Zinsstruktur in der Schweiz. Swiss J. Econ. Stat. 1, 39-50 (1990)

Bernanke, B.S.: On the predictive power of interest rates and interest rate spreads. New Engl. Econ. Rev. November / December, 51-68 (1990)

Bernard, H., Gerlach, S.: Does the term structure predict recessions? The international evidence. Int. J. Financ. Econ. 3, 195-215 (1998)

Bisignano, J.R.: A study of efficiency and volatility in government securities markets. mimeo, BIS (1987)

Boudoukh, J., Richardson, M., Whitelaw, R.: The information in long-maturity foward rates: Implications for exchange rates and the forward premium anomaly. NBWER Working Paper 11840 (2005)

Büttler, H-J.: The information content of the yield curve. In: BIS Paper No 12, Market functioning and central bank policy, pp. 298-328 (2002)

Capitelli, R.: Die Zinsstruktur der Schweiz: Ein faktoranalytischer Ansatz im Frequenzbereich. Haag und Herchen, Frankfurt am Main (1983)

Clarida, R., Galí, J., Gertler, M.: Monetary policy rules in practice: some international evidence. Eur. Econ. Rev. 42, 1033-1067 (1998)

Cox, J.C., Ingersoll, J.E. Jr, Ross, S.A.: An intertemporal general equilibrium model of asset prices. Econometrica 53, 363-384 (1985)

Cuthbertson, K.: Quantitative financial economics. Wiley, Chichester (1996) 
Deppner, C.: Die Schätzung der Zinsstruktur und deren Bedeutung in der Kapitalmarkttheorie - Eine empirische Untersuchung auf Basis von multiplen Regressions- und linearen Optimierungsmodellen mit Daten der schweizerischen Rentenmarktes. Rosch-Buch, Hallstadt (1992)

Estrella, A., Hardouvelis, G.A.: The term structure as a predictor of real economic activity. J. Financ. 46(2), 555-576 (1991)

Estrella, A., Mishkin, F.: The predictive power of the term structure of interest rates in Europe and the United States: implications for the European Central Bank. Eur. Econ. Rev. 41, 1375-1401 (1997)

Estrella, A., Mishkin, F.S.: Predicting US recessions: financial variables as leading indicators. Rev. Econ. Stat. 80, 45-61 (1998)

Fama, E.F.: Term-structure forecasts of interest rates, inflation and real returns. J. Monet. Econs. 25(1), 59-76 (1990)

Fisher, I.: Appreciation and interest. Publications of the American Economic Association, pp. 23-29 and 88-92 (1896)

Gerlach, S., Smets, F.: The term structure of euro-rates: some evidence in support of the expectations hypothesis. J. Int. Money Financ. 16, 305-321 (1997)

Gerlach, S., Smets, F.: Exchange rate regimes and the expectations hypothesis of the term structure. In: Angeloni, I., Rovelli, R. (eds) Monetary Policy and Interest Rates. MacMillan Press (1998)

Gerlach-Kristen, P.: The impact of the new Swiss monetary policy framework on inflation expectations. mimeo, SNB (2005)

Gerlach-Kristen, P.: Estimating a two-pillar Phillips curve for Switzerland. Swiss National Bank Working Paper 9 (2006)

Greene, W.H.: Econometric Analysis, Prentice-Hall, London (1997)

Hardouvelis, G.A.: The term structure spread and future changes in long and short rates in the G7 countries. J. Monet. Econ. 33, 255-283 (1994)

Heller, D.: Zinskurven und ihr Informationsgehalt für die Geldpolitik, Quartalsheft SNB 2, 167-176 (1997)

Hildebrand, P.: Vom Monetarismus zur Inflationsprognose: Dreissig Jahre schweizerische Geldpolitik, lecture given at the University of Bern, Nov 23, available at www.snb.ch (2004)

Hildebrand, P.: Monetary policy and financial markets. Financ. Markets Portf. Manage. 20(1), 7-18 (2006)

Hsu, C., Kugler, P.: Term premium and volatility: a nonlinear analysis of the Swiss interest rates. Swiss J. Econ. Stat. 132(2), 153-176 (1996)

Hsu, C., Kugler, P.: The revival of the expectations hypothesis of the US term structure of interest rates. Econ. Lett. 55, 115-120 (1997)

Jordan, T.J., Kugler, P.: Implementing Swiss monetary policy: Steering the 3M-LIBOR with repo transactions, mimeo, SNB and University of Basel (2003)

Jordan, T.J., Peytrignet, M., Rich, G.: The role of M3 in the policy analysis of the Swiss National Bank. In: Hans-Joachim, K., Willecke, C. (eds) Monetary Analysis: Tools and Applications. European Central Bank, Frankfurt, pp. 47-62 (2001)

Jorion, P., Mishkin, F.: A multicountry comparison of term-structure forecasts at long horizons. J. Financ. Econ. 29, 59-80 (1991)

Kugler, P.: An empirical note on the term structure and interest rate stabilization policies. Quart. J. Econ. 103, 789-792 (1988)

Kugler, P.: The expectations hypothesis and interest rate volatility on the euromarket: some empirical results. In: Kähler, J., Kugler, P. (eds) Econometric Analysis of Financial markets. PhysicaVerlag (1994)

Kugler, P.: The term structure of interest rates and regime shifts: some empirical results. Econ. Lett. 59, 121-126 (1996)

Kugler, P.: Central bank policy reaction and the expectations hypothesis of the term structure. Int. J. Financ. Econ. 2, 217-224 (1997)

Kugler, P.: The term premium, time varying interest rate volatility and central bank policy reaction. Econ. Lett. 76, 311-316 (2002)

Mankiw, G.N., Miron, J.A.: The changing behavior of the term structure of interest rates. Quart. J. Econ. 101, 211-228 (1986) 
McCallum, B.T.: Monetary policy and the term structure of interest rates. NBER Working Paper 4938 (1994)

Meier, I.: Estimating the term structure of interest rates: the Swiss case. mimeo, University of Bern (1999)

Mishkin, F.S.: The information in the longer maturity term structure about future inflation. Quart. J. Econ. 105(3), 815-828 (1990)

Mishkin, F.S.: A multi-country study of the information in the shorter maturity term structure about future inflation. J. Int. Money Financ. 10, 2-22 (1991)

Mishkin, F.S.: Inflation targeting. In: Brian, S., Vane, H.R. (eds), An encyclopedia of macroeconomics, Edward Elgar, Cheltenham, UK (2002)

Olivei, G.P.: Switzerland's approach to monetary policy. Federal Reserve Bank of Boston New England Economic Review, pp. 57-60 (2002)

Peytrignet, M.: Swiss monetary policy under a flexible exchange rate regime: monetary targets in practice. In: Bank of Canada, Money, Monetary policy, and transmission mechanisms, pp. 193-219 (1999)

Rich, G.: Swiss monetary targeting 1974-1996: the role of internal policy analysis. European Central Bank Working Paper 236 (2003)

Shiller, R.J.: The term structure of interest rates. In: Friedman, B.M., Hahn, F.H. (eds) Handbook of Economics. North Holland, Amsterdam (1990)

Swiss National Bank: Quartalsheft 1, 51-56 (1983)

Swiss National Bank: Quartalsheft 4, 8-13 (1999)

Swiss National Bank: Quartalsheft 2, 64-73 (2002)

Svensson, L.E.O.: Inflation forecast targeting: Implementing and monitoring inflation targets. Eur Econ. Rev. 41, 1111-1146 (1997)

Taylor, J.B.: Discretion versus policy rules in practice. Carnegie-Rochester Conf. Ser. Publ. Policy 39, 195-214 (1993)

Tobler, J.: Ein zweistufiges Verfahren zur Schätzung der Zinskurve. Swiss J. Econ. Stat. 135(1), 41-74 (1999)

Unternährer, M.: Geldpolitik, Zinsspread und realwirtschaftliche Aktivität in der Schweiz, Institut für empirische Wirtschaftsforschung der Universität Zürich, Band 39, Verlag Schellenberg, Winterthur (1997)

Woodford, M.: Nonstandard indicators for monetary policy: Can their usefulness be judged from forecasting regressions? In: Gregory Mankiw, N. (ed) Monetary Policy. NBER and University of Chicago Press (1994)

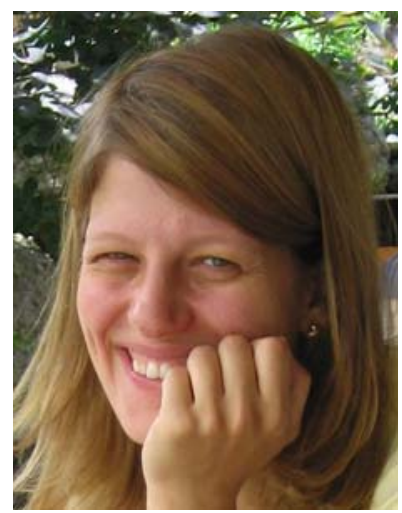

Petra Gerlach-Kristen is an economist in the research department of the Swiss National Bank and teaches at the University of Basel. Previously, she was a visiting assistant professor at the University of Hong Kong. Her research focuses on the interest rate setting behaviour of central banks and the Swiss economy. 